\title{
Researcher's personal experiences as a method of embodiment research
}

\author{
ORIGINAL ARTICLES
}

\author{
Dominika Byczkowska-0wczarek \\ University of Lodz, Poland | dominika.byczkowska@wp.pl
}

\begin{abstract}
The article aims at presenting the technique of data collection, hereinafter referred to as autoethnography. The discussed concept will be presented in its two variants: evocative and analytic autoethnography. Reference will be made to some specific key features of the latter. The discussion will also cover the issue of usefulness of the analytic autoethnography in the GTM-based research and in the symbolic interaction-oriented research. I am also going to present an example of the use of analytic autoethnography in the embodiment research and a way of applying one to the GTM procedures, i.e. open coding. At the end of this paper, the discussion will revolve around the advantages and disadvantages of the method in question. Finally, I will voice my doubts about the applicability of the said method.
\end{abstract}

Keywords: autoethnography, Grounded Theory Methodology, embodiment, dance.

recived 12.03.2014 | revision 3.06.2014 | accepted 23.06.2014

\section{Introduction}

As a researcher interested in any kind of human activities who looks at humans from an interactionist perspective and has been inspired by one of the dance shows, I embarked on the project related to the social world of ballroom dancing. As is often the case with the Grounded Theory Methodology-based research projects (hereinafter referred to as GTM-based research projects), the data have revealed some unpredictable, social phenomena that have been unknown to me so far. It turned out that studying any human activity related to the bodily experience like, for example, dancing (Desmond, 1997; Rambo Ronai, 1992; Rambo Ronai \& Cross, 1998; Rambo Ronai \& Ellis, 1989), yoga practices (Konecki, 2010) or rock climbing, entails the necessity to develop specific data collection methods. As the social identities and the social roles of the ballroom dancers require having a proper body, the body should have the right shape and proper looks. It should react correctly and be able to communicate meanings through movement. That is why social actors focus on preparing the right body while preparing their social activities.

The research into the social bodily practice reveals some problem areas arising out of the fact that bodily experience is only partly communicable in verbal terms, which encouraged me to refer to my own experiences as a dancer. During the research I realized that my own experiences match the ones the interviewees talked about and thus they can be used for the purpose of the analysis, providing data that are not intersubjectively available. I have been learning belly dance for the last four and a half years and I started to notice the phenomena described by my interviewees during my own lessons. This led me to the conclusion that using one's own body for social research is crucial for understanding the phenomena that are not available intersubjectively. 


\section{What is autoethnography?}

Autoethnography is one of the data collecting techniques which I have used in my GTM-based study. In this method the researcher acts as an element of the phenomenon researched, sometimes the main one (Wall, 2008). Autoethnography focuses on understanding oneself, instead of or additionally to understanding others. The most important thing is autoreflection and the analysis of each part of the experience connected with the phenomena under study (Gobo, 2008).

In the literature on the subject there are various definitions of autoethnography available. In the foregoing I present some of them, following Norman K. Denzin's (2006) argumentation:

- Carolyn Ellis (2004) claims that: "Autoethnography is research, writing and method that connect the autobiographical and personal to the cultural and social. This form usually features concrete action, emotion, embodiment, self-consciousness, and introspection" (p. 19).

- Tami Spry (2001) defines autobiography as: "Autoethnography is a self-narrative that criticizes the situatedness of self and others in social context" (p. 710).

- According to Mark Neumann (1996) autoethnographic texts: "democratize the representational sphere of culture by locating the particular experiences of individuals in tension with dominant expressions of discursive power" (p. 189).

- Stacy Holman Jones (2005) says that: Autoethnography "is a blurred genre... a response to the call... it is setting a scene, telling a story, weaving intricate connections between life and art... making a text present... refusing categorization... believing that words matter and writing toward the moment when the point of creating autoethnographic texts is to change the world" (p. 765).

- Despite the fact that there are many definitions of this research method, one may find some similarities between them. Namely, they all point to the links between the individual and personal experience: they emphasize the fact that it is a new way of gaining empirical data: they all stress the connection between the culture, the art and the fact of experiencing certain phenomena personally and than in their textual form.

\section{Kinds of autoethnography}

Leon Anderson (2006) distinguishes two kinds of autoethnography. The first one referred to as evocative au- toethnography is rooted in the postmodern tradition and requires mainly the description of the researcher's own experiences and feelings. Scientists who use this type of autoethnography distance themselves from the ethnographic tradition and consider it as a separate technique (Ellis \& Bochner, 2006). The second type is analytic autoethnography (hereinafter referred to as AA), rooted in the ethnographic tradition and Chicago school (Anderson, 2006). One of the most significant differences between them is that evocative autoethnography has less methodological limitations. Researchers who use this method concentrate more on their own feelings, dreams, their specific point of view, whereas $A A$ is limited by its main aim, i.e. the analysis of data and comparison of the outcomes with other empirical data (an important procedure in the GTM is that of constant comparison). The foregoing sections include the presentation of Anderson's (2006) five key features of $A A$ which show how it should be applied to give reliable results.

The first one is complete member researcher (hereinafter referred to as CMR) status (Rambo Ronai, 1992). This means that a researcher must be a full member of the group under study. He must identify himself with a group, a social world, a social environment, or a subculture and he should be perceived as a regular member by other social actors. There are at least two ways of becoming a complete member, i.e. becoming an opportunistic CMR or a convert CMR.

An opportunistic CMR is a person who usually joins the group or subculture due to his life course: he may be born in the group or he may join it naturally. In any circumstances joining the researched group takes place earlier then the research project starts.

Convert CMRs are those researchers who start their participation in the group from the data collection-oriented actions. In the course of the research, they become more and more engaged in the phenomenon under study (Anderson, 2006).

CMRs are those researchers who get closest to the phenomenon researched, which may be perceived as an advantage or a disadvantage. The advantage is of course the fact that they may gain knowledge and experience which would be impossible to gain by a distant researcher. The disadvantage is that for CMRs it is very difficult to have a proper distance which is necessary for the analysis of data.

There is also another disadvantage, or - to be more precise - a potential disadvantage. Namely, members of a certain group usually differ as to their specific member roles. Consequently, having one role researchers can only obtain fragmentary data, which makes the picture limited. What 
is more, a researcher always has his own scientific point of view by which he differs from others in the research field.

According to Anderson analytic reflexivity is the second important feature of a well-conducted AA. It implies the researcher's awareness of his relatedness to the research field, to the phenomenon and the group under study. The researcher is able to understand the experiences and actions of others, because of the fact that he is one of them, unlike in ethnography, which focuses on others rather than on the self. Thanks to this, the researcher may interpret actions of other social actors. Unlike in ethnography, $A A$ researchers try to see the world not only through the eyes of the others, but mainly through their own eyes. This enables them to learn a lot about the phenomenon researched from an insider's perspective.

Narrative visibility of the researcher's self is the third feature of the AA. It is held as necessary, because of the fact that the data generated using this method have great influence on the researcher's self. The $A A$ is not only about collecting facts, but also about reconstructing the researcher's point of view (Anderson, 2006). The researcher should be visible in the text, which means that his opinions, emotions, doubts, feelings, problems etc. are an important part of the data and should also be analysed.

Dialogue with informants beyond the self points to another feature of the AA (Anderson, 2006). Namely, the data is only a set of researcher's impressions but the researcher can reach outside his own self. This makes it more possible to extrapolate the results on the experiences of other actors, on the social actions and various phenomena.

Commitment to theoretical analysis (Anderson, 2006) is the fifth feature of the AA. It is important to bear in mind our main aim, which is gaining scientific knowledge and analysing the data in order to construct a theory and understand the phenomenon researched as thoroughly as possible. The aim is not to write down one's own experiences, since this may be done in a journal. The difference between a journal written just for oneself and the $A A$ is that in the second case we use the data collection technique which is our tool, so we have methodological limitations and challenges.

In my research on the social subworld of ballroom dancing which I have conducted for the last five years I have used the GTM and qualitative research techniques ${ }^{1}$, including the $A A$. I have also used Symbolic Interactionism

\footnotetext{
The research material includes 20 interviews, 7 photo elicited interviews, 4 video elicited interviews, 5 observations, autoethnographic reports from dance classes, over 300 photos, 12 films from ballroom contests and dance lessons, ballerina's autobiography, the transcription
}

to formulate the findings in order to construe the theory. Therefore, in the section that follows I present some relations between the $A A$, the GTM and Symbolic Interactionism.

\section{Analytic Autoethnography, Grounded Theory Methodology and Symbolic Interactionism}

In qualitative research, the researcher is considered to be the most important research tool. In $A A$ the researcher uses himself to get as close to the research phenomenon as possible, which makes it a very demanding technique. On the one hand, the technique requires discipline, analytic reflectivity and methodological experience. On the other hand, a researcher must be open-minded, he must observe himself well, note all the situations, thoughts and actions that happen to him. As it is in ethnography, in $A A$ one must try to spot also the most obvious events, which is even more demanding when you observe your own self.

As one of the GTM rules says, the research methods should be chosen according to the phenomenon researched. This means that when studying some challenging phenomenon, such as embodiment (Kubinowski, 2003), closed groups (prisoners, thieves etc.) (Vryan, 2006) we must customise our methodological tools in order to gain the best and most reliable data possible. In my embodiment research, I have encountered problems in understanding the non-verbally transmitted ideas, rules that were literally incorporated in the interviewees' bodies. Therefore, I decided to analyse my own dancing experience, the changes that have happened to me, for example, those related to the perception of the body, the shape of body, the way other female bodies are perceived or the ways of gaining control and consciousness of one's body. This was very useful in understanding the persons under study, despite the fact that different dance genres were practiced (e.g. ballroom dancing, belly dancing).

$A A$ can be applied in a GTM-based study because it is proper for all kinds of coding procedures, like other texts, movies, photographs. AA may take various textual and visual forms but thanks to the GTM procedures it may be easily analysed with the use of initial and focused coding (Charmaz, 2006). In vivo codes may come from $A A$, as the researcher/participant could give those terms a deeper meaning, knowing them from his own experience.

of a radio program and Polish Dance Association's rules for sports ballroom dancing. 
$A A$ is rooted in a realistic, ethnographic tradition and in qualitative research. One may notice some interest in the biographical backgrounds in the works of Robert Park and in Nels Anderson's Hobo. What is more, some of Everett Hughes's students were also researching their natural environment. However, the difference between $A A$ and their research is that they concentrated more on the situation that is on the researcher's feelings and emotions, as regards the social phenomena (Anderson, 2006). Despite studying their own environment, they still had a distant perspective, concentrating on ethnography rather than on their own experiences as insiders.

One of the basic assumptions formulated by Symbolic Interactionism (SI) is that individuals act according to the meaning ascribed to, among others, other peoples' actions and objects (Blumer, 1986). AA shows this process from the first-hand perspective. Researchers may observe themselves in the process of gaining a specific group perspective, obtaining new ways of perceiving people, objects and also one's own self. However, the data obtained in this way, should be analysed by other researchers who are able to study the process of changing and gaining meanings from the distance, as it is necessary

The process of interpretation which is so important in every SI research (Blumer, 1986, p. 79) is inscribed in the AA. As an individual starts to be part of the social world that is researched or starts a new activity, the world also starts to change his interpretation processes. When new experiences appear, they are usually connected with new definitions of the given situation, with the change of meanings of the well-known objects etc. The AA allows us to observe this process in the way it is presented below.

\section{$A A$ in bodily experience research}

There are many examples of the $A A$ studies in the field of embodiment research. They concern medical procedures (Hoffmann-Riem, 1994), therapeutic relations with one's body (Lussier-Ley, 2010), ballroom dancing (Picard, 2002) or adoption problems (Wall, 2008). One of the most popular examples of research on dance and embodiment is Carol Rambo-Ronai's (1992) strip dance study. The researcher was an erotic dancer herself. She analysed the data collected in the interviews with other dancers and wrote them down in the field notes. In many of her texts, cooperating with other researchers she studied the way her body changes and how it may be used as a paid sexual turn-on (Rambo-Ronai \& Ellis, 1989), as a factor in constructing identity (Rambo Ronai \& Cross, 1998) or as the commoditisation of dancer's body (Rambo, Presley, \& Mynatt, 2006). Despite the fact that Rambo's autoethnography was rather elicited that analytic, the research based on the personal experience is highly disciplined and provides a good insight into her experience.

I believe that understanding oneself and other people (along the lines of Rambo's research) is very important in the educational process of all the social science students and thus in one of the courses that I taught autoethnographic exercises ${ }^{2}$ were used. During the first semester I did classes for my students on "Dance and body-sociological perspective". We analysed texts about theoretical, empirical and methodological issues related to body, embodiment and dance. We also analysed visual data like films and photographs. I wanted to teach my students that, when it comes to the embodiment research, one should combine various methods in order to gain the richest data. To archieve my aim I decided that they needed an exercise on analytic autoethnography, so we organized a dance lesson. I had learned belly dance for four and a half years and I had had some experience in teaching. I conducted the lesson myself. There were fifteen students who participated in this exercise, the majority of whom were girls. There were only two boys. The lesson took place in a dance hall equipped with big mirrors which are very useful when teaching or learning dance. We had a short warm up, with some elements of yoga that were introduced by my friend who also participated in the lesson. Then, we exercised belly dance steps and moves, and at the end of the lesson we did some stretching. After this lesson, my students had two weeks to submit their reports from this autoethnographic exercise. Later, they were supposed to produce essays based on those reports, describing bodily experiences from different theoretical perspectives (phenomenology, dramaturgical, dance studies etc.). In what follows I present two parts of the autoethnographic reports produced by my students. The first was prepared by a girl who had never tried belly dance before (Table 1). The second one was written by a girl who had danced before, but changed her style to bharatanathyan ${ }^{3}$, i.e. an Indian traditional dance style (Table 2). In the first column I present the parts of the essays written by my students. In the second column I present the way they may be coded.

Autoethnographic exercises are not referred to as autoethnography, because the students were not CMRs and they used this method for a very short period of time, on and after the dance classes.

The students and the teachers agreed to have the data quoted. 
Distraction - observing my own body in the mirror and the effort to concentrate on exercising the positions in a proper way. I think none of the steps was executed properly.

Embarrassing movements made me concentrate on the parts of my body which I mostly refuse to accept, i.e. breasts, thigh, butt.

Finally, I tied my sweatshirt around my hips to cover my backside.

Looking for an ally in my friend (joking, laughing, commenting) to reduce the tension and show false distance to my body and figure.

Lack of control over my body. I tried to copy a shown pose with no success. I felt pain in my arms

Feeling jellylike when shaking my hips. I stopped it very quickly. I was very ashamed observing myself in the mirror.

Bum warm-up - I have exercised this way for the first time I was astonished that one may exercise the body this way.
Distancing from the observation of the body.

Comparing one's own body to the teacher's body.

Emotions connected with the way the body moves.

Emotions connected with the way the body looks.

Actions undertaken to neutralise the emotions towards the bodypretending that the body is not there by using objects.

Actions undertaken to neutralise the emotions - looking for an ally.

Actions undertaken to neutralize emotions - imitating other emotions.

Lack of contact and control over the body.

Emotions connected with body and actions undertaken to neutralise them - stopping.

Distancing from the body-observing.

Discovering new ways to "use" the body.

Table 2

Initial coding in the AA; example 2

\section{Example 2}

Memorable pain in my hands held in the horizontal position came back. I expected it, but not to that extent. Also my exercised hips got a little lazy. I was sure I could afford a bigger scope. It's like trying to move your hand, which got benumbed during sleep, from behind of your head. It will not serve us as usual. You attempt and in the middle of its way you see your inert hand landing on your face. It was sad and disappointing experience, when you know the moves and remember yourself doing them, but you cannot repeat it. It makes me feel instantaneous dance impotency.

\section{Open coding procedure}

Recalling past bodily experiences.

Referring to past skills.

Surprise by the information from the body.

Lacking control over the body.

Body treated as a (defiant) servant.

Lacking of control over the body, which causes negative emotions. Recalling past bodily experience and noticing changes in the body.
The following categories may be generated from these data. Social actor's attitude towards the body:

- comparing with other bodies,

- discovering new ways to use one's body,

- distancing from the body,

- recalling past bodily skills.

In most general terms, the actor's attitude consists in observing one's body from a distance and producing mainly negative emotions towards the body, which causes: actions undertaken to neutralise emotions such as:

- looking for an ally,

- imitating the emotions of others,

- stopping an activity,

- pretending the body is not there by using objects to hide it.
Supposedly, some of these categories might not have been obtainable by using another method, such as observation. They definitely show an insider's perspective, their emotions and personal attitude towards their bodies. They also present some of the actions taken because of these emotions, and - what is important - they show cause and effect.

As we may observe in these texts, in $A A$ research time is vital. An $A A$ report should be prepared immediately after an action is undertaken. Then, our internal censors will not have time to influence our view on the experience and we will have less time to forget it. In these citations from the students' reports language is also important. It shows emotions, restraint towards one's own body and lack of control. Some of the expressions, like ally, reducing 
tension, instantaneous dance impotency that are used in parts of these reports could be used in vivo codes or sensitising concepts (Charmaz, 2006).

\section{Advantages, disadvantages and doubts about the method}

One of the most important advantages of $A A$ is that it gives an insight into the participant's/insider's experience and knowledge. Therefore, it makes it possible to deepen the research results (Anderson, 2006). Also, interviews or observation of an outside researcher, irrespective of their scope, would have been incapable of producing such depth, richness and completeness of the data, as may be gathered via fully-immersive (and documented) self-observation, self-interviewing and self-analysis (Vryan, 2006).

When used with proper methodological discipline, the $A A$ gives the possibility to deepen the research results obtained with the use of other methods and extrapolate results on others, i.e. beside the researcher's self. The result of studying the aspects of one's own life has relevance beyond one's own personal experience, giving a unique perspective at the same time.

One feature of $A A$ which may not, in my opinion, be perceived as an advantage or disadvantage is the fact that it does not take one special form. It may become a personal reflection, memoir, journal, autobiography, autobiographical ethnography etc. (Charmaz, 2006). That is why when producing $A A$, a researcher should not include fiction, dreams, alternative scenarios, unless he makes it clear. If a researcher includes unreal elements in his study, like dreams or fiction it is no longer a first-hand ethnography. On the other hand, it enables the researcher to adjust this technique to his own needs and to the phenomena under study. This has its advantages because the form may be adjusted to the researcher-author and to the phenomenon. The limitations of form do not bring us closer to understanding the social reality. On the other hand, the $A A$ author must remember about the aim of the method.

Autoethnographic reports sometimes seem messy, as if the author put each thought (i.e. impressions, reflections, fiction, dreams or poetry) that came to their mind onto the paper. In some respect it is good, because it does not limit the researcher. Self-censorship is not useful for any research method. Admittedly, it is important to separate the reality from what did not happen. That is one of the differences between a personal journal, written for oneself, and preparing an autoethnographic report.
The method under study, as all other methods also has its disadvantages and limitations. One of the most obvious problems is extrapolating the results onto other cases and building theory based on them. As was pointed out above, to be able to extrapolate the results onto other cases, to build a theory depending on these data, one must be methodologically well-disciplined and always remember about the general aim, which is gaining the research data.

The researcher's role is also demanding. He may not have the freedom to withdraw from the setting or experience, although he may withdraw from studying the phenomenon. There is also something that may be referred to as the problem of "the tigger" from the story Winnie-thePooh. Just like this book character, the researcher may not be sure about his role in the social setting. Also, he may not be sure about his own identity in the research field.

The elevation of the autobiographical element to such a degree that the ethnographer becomes more memorable than the ethnography, the self may become more absorbing than other social actors is the disadvantage from the very sense of this method. However, when a researcher is experienced and works for the general aim, i.e. collecting the analysable data, it may be easily overcome (Atkinson, 2006).

Another problematic issue is the fact that groups usually produce specific member roles. This means, that members seldom have uniform sets of beliefs, values, experiences and $A A$ is always partial (Anderson, 2006). But just like other qualitative methods, for example interview or observation, it would always give a one-sided point of view. It is the responsibility of the research group to use methodological triangulation (Denzin, 2009) hand in hand with the constant comparative method and various data collection techniques in order to obtain the best results.

\section{Conclusion}

Generally speaking, the $A A$ may be a very useful research technique, as long as some of the conditions, mainly concerning the researcher, would be taken into account. Firstly, a researcher must know his role very well. All the time he should be aware of the main aim of experiencing a certain social phenomenon, i.e. gaining and deepening the analysable data. Secondly, the researcher doing the research on himself, must be well-disciplined in terms of limiting himself to gathering only the data that really exist, which means omission of dreams, alternative scenarios etc. Of course, the fact that they appear is interesting and may be valuable for the analysis, but this 
differentiation between the actual facts and one's imagination must be pointed out in the report. Making contact with others who experience the same process or are the members of the group under study is also very useful and makes it more possible to extrapolate the data.

Thirdly, AA is a useful method, but it is still a method of data gathering. Neither does it show a wider picture, nor the description of all the group roles or possible perspectives in the group under study. It is what it is: a description of one point of view, one specific personal experience that is influenced by the researcher's personal history and individual features. As long as $A A$ is treated in this way, it may be a very useful technique.

Fourthly, the data obtained with the use of AA must be analysed according to the normal analytical procedures, for example those of the GTM. One of them is triangulation, especially the researcher's and methodological triangulation (Denzin, 2009) that implies working in a group of investigators who would have a distance towards the data, which the researcher who did his AA misses. Analysing the data in a group of investigators enables us to see more general problems regarding the experience of a single person. In turn, the notion of the methodological triangulation means that the $A A$ should be only a part of the research process and the data obtained with the use of this method should be compared with the data from the interviews, visual techniques, observation or other methods.

The fifth, but in my opinion one of the most interesting and ethically important features of $A A$ is that it really enables a researcher to understand the persons under study, both in the theoretical and practical dimension. Using one's own body, emotions, confronting personally with difficult or pleasant experiences, without keeping distance, may be a very illuminating experience and it will surely make us understand the persons under study better, which is - after all - the aim of all social scientists.

\section{References}

Anderson, L. (2006). Analytic Autoethnography. Journal of Contemporary Ethnography, 35(4), 375-395. doi: 10.1177/ 0891241605280449

Atkinson, P. (2006). Rescuing Autoethnography. Journal of Contemporary Ethnography, 35(4), 400-404. doi: 10.1177/ 0891241606286980

Blumer, H. (1986). Symbolic Interactionism: perspective and method. Los Angeles, CA: University of California Press.
Charmaz, K. (2006). The Power of Names. Journal of Contemporary Ethnography, 35(4), 396-399. doi: 10.1177/ 0891241606286983

Denzin, N. K. (2006). Analytic Autoethnography, or Déjà Vu all Over Again. Journal of Contemporary Ethnography, 35(4), 419-428. doi: 10.1177/0891241606286985

Denzin, N. K. (2009). The research act: a theoretical introduction to sociological methods. New Brunswick, NJ: Aldine Transaction.

Desmond, J. C. (Ed.). (1997). Meaning in Motion: New Cultural Studies of Dance. Durham: Duke University Press.

Ellis, C. (2004). The ethnographic I: A methodological novel about teaching and doing autoethnography. Walnut Creek, CA: AltaMira.

Ellis, C. S., \& Bochner, A. P. (2006). Analyzing Analytic Autoethnography: An Autopsy.Journal of Contemporary Ethnography, 35(4), 429-449. doi: 10.1177/0891241606286979 Gobo, G. (2008) Doing ethnography. Los Angeles, CA: Sage. Hoffmann-Riem, C. (1994). Losing a symbolically significant part of the body. In Elementare Phänomene der Lebenssituation. Weinheim: Deutscher Studien Verlag.

Holman Jones, S. (2005). Autoethnography: Making the personal political. In. N. K. Denzin, \& Y. S. Lincoln (Eds.) Handbook of Qualitative Research ( $3^{\text {rd }}$ ed., pp. 763-791). Thousand Oaks, CA: Sage.

Konecki, K. T. (2010). Wywiad na podstawie filmów w badaniach praktyki jogi - na przykładzie badań cielesności i gestów w społecznym świecie praktyki jogi. In J. Leoński\& M. Fiternicka-Gorzko (Eds.), Kultury, subkultury iświaty spoteczne w badaniach jakościowych (pp. 303-335). Szczecin: Uniwersytet Szczeciński.

Kubinowski, D. (2003). Kinaestetic Understanding in Dance Education, Therapy and Research. Studia Choreologica, 5, 49-111.

Lussier-Ley, C. (2010). Dialoguing with the body: a self study in relational pedagogy through embodiment and the therapeutic relationship. The Qualitative Report, 15(1), 197-214.

Neumann, M. (1996). Collecting ourselves at the end of the century. In. C. Ellis, \& A. Bochner (Eds.), Composing ethnography: Alternative forms of qualitative writing (pp. 172-198). Walnut Creek, CA: AltaMira Press.

Picard, C. J. (2002). Dancing through different worlds: an autoethnography of the interactive body and virtual emotions in ballroom dance. Qualitative Inquiry, 8(3), 348-361. doi: 10.1177/10778004008003009

Rambo Ronai, C. (1992) Managing aging in young adulthood: The aging table dancer. Journal of Aging Studies. 6(4), 307-317. doi: 089040659290014W 
Rambo Ronai, C., \& Cross, R. (1998). Dancing with identity: narrative resistance strategies of male and female stripteasers. Deviant Behavior, 19(2), 99-119. doi: 10.1080/ 01639625.1998.9968078

Rambo Ronai, C., \& Ellis, C. (1989). Turn-ons for money. Journal of Contemporary Ethnography, 18(3), 271-298. doi: 10.1177/089124189018003002

Rambo, C., Presley, R. S., \& Mynatt, D. (2006). Claiming the bodies of exotic dancers: the problematic discourse of commodification. In. D. Waskul, \& P. Vannini (Eds.), Body/embodiment: symbolic interaction and the sociology of the body (pp. 213-228). Aldershot: Ashgate.
Spry, T. (2001). Performing autoethnography: An embodied methodological praxis. Qualitative Inquiry, 7(6), 706-732. doi: 10.1177/107780040100700605

Vryan, K. D. (2006). Expanding Analytic Autoethnography and Enhancing Its Potential. Journal of Contemporary Ethnography, 35(4), 405-409. doi: 10.1177/0891241606286977

Wall, S. (2008). Easier said, than done: writing an autoethnography. International Journal of Qualitative Methods, $7(1), 38-53$. 